\title{
Fuzzy logic energy management system of food manufacturing processes
}

\section{Serhii Baliuta ${ }^{1}$, Liudmyla Kopylova ${ }^{1}$, Iuliia Kuievda ${ }^{1}$, Valerii Kuevda $^{1}$, Olena Kovalchuk ${ }^{2}$}

\author{
1 - National University of Food Technologies, Kyiv, Ukraine \\ 2 - Lutsk National Technical University, Lutsk, Ukraine
}

Keywords:

Electricity

Energy

Control

Fuzzy

Article history:

Received 12.04.2019

Received in revised

form 10.10.2019

Accepted 30.03.2020

\section{Corresponding}

author:

Iuliia Kuievda

E-mail:

julika@gmail.com

DOI: $10.24263 / 2304-$

974X-2020-9-1-19

\section{Abstract}

Introduction. The research is conducted to justify the method of increasing the efficiency of electrical power use in food production processes, which is based on the algorithms of fuzzy power management system.

Materials and methods. The study is based on optimal and fuzzy control methods, such as Mamdani and Sugeno algorithms. Computer simulation was performed using MATLAB Simulink.

Results and discussion. The control criterion of power supply of food production is formulated in the form of a functional minimization problem, which depends on the expected value of active and reactive power losses, active and reactive power losses at the level of secondary substations and individual load nodes. Maintaining energy efficient voltages in the power supply system nodes is chosen as a control task. It is determined the dependence of energy efficient voltages on the nominal voltage of the power system, the active resistance of its segments, the power and the coefficient of linearized static load characteristics at the network nodes, the equivalent active resistance, the nominal power, open circuit and short circuit losses of secondary substation transformers. To solve the control problem, an algorithm is synthesized using fuzzy controllers at the levels of the primary and secondary substations. In particular, it is determined that the input signals of the secondary substation fuzzy regulator should be the deviation from the energy efficient voltages and the rate of voltage change, and the output signals should be the transformer voltage and the actuation delay. Using numerical methods it is shown that this algorithm can reduce electricity losses in food production processes up to $7 \%$ compared to classical voltage regulation methods.

Conclusions. The fuzzy system method under study ensures that energy-efficient voltage levels are maintained at the distribution network nodes when the voltage of the power source or the consumer loads are changed. 


\section{Glossary}

FMP - food manufacturing processes

PSDS FMP - power supply and distribution system of FPM

DEG - district electric grid

$\mathrm{EPG}$ - electric power grid

SS - secondary substation

PS - primary substation

SCL - static characteristics of complex load

LV - low voltage

HV - high voltage

MFA - Mamdani Fuzzy Algorithm

SFA - Sugeno Fuzzy Algorithm

MF - membership function

SCADA - supervisory control and data acquisition

\section{Introduction}

Electricity consumption in food manufacturing is calculated in the tens of megawatts, and needs to be reduced to create more sustainable food production branch of economics and prevent waste of resources [13]. Such problem can be solved within the scope of automated control of energy consumption and supply of food manufacturing processes (FMP). Methods and models for this kind of solution are considered in wide range of scientific studies as described below.

In particular, the research [4] outlines the main tasks that should be solved by automated control systems for power supply and distribution of technological processes. At the same time, the main attention is paid to the issues of calculation of power system operation modes. The studies [22, 24, 25] consider the issues of power management by means of dispatching operations based on microprocessor technology. Methods and means of power management with the help of local systems of reactive power compensation control and voltage regulation in distribution networks are presented in [1]. The research [11] proposes a two-level voltage regulation system in the distribution electrical network, and the studies [22, 19] discuss the issue of voltage regulation in the electrical network using fuzzy logic.

According [9] it is promising to build power management systems with the use of a multifunctional meter on the lower level for operating parameters of the grid, which allows to measure voltages and currents in all three phases, active and reactive power, as well as electricity costs and has electromagnetic compatibility with $0.4-10 \mathrm{kV}$ devices. The system proposed in [9] uses the digital output of the meter to connect to industrial communication networks based on Modbus and Profibus, and at the top level - SCADA systems. Analysis of this system showed that the use of SCADA systems without the use of special application software that provides control functions does not solve the problem of building effective control systems, because they perform a limited amount of functions related only to the collection of measured data, remote control switching equipment, archiving and displaying information on mnemonic circuits.

Recently, modern industrial controllers and SCADA systems have been widely used in the design of automated energy management systems $[16,5,7]$. The use of these technical tools allows to solve in real time the problems of commercial metering of power consumption, technical logging and monitoring of electrical loads of food industry 
enterprises, the interaction of the operator with the information system, which is the basis for solving the problems of power management of food industry enterprise.

The analysis of studies [21, 16, 18, 8, 20] showed that the structural solutions, mathematical models and control methods presented in them provide only the function of controlling the parameters of the power system. However, these tools do not provide the implementation of the monitoring and optimal control functions which allow obtaining the main economic effect [12].

The main goal of this research is to justify designing principles of the automated energy management system of food manufacturing processes on the basis of mathematical models, methods of fuzzy logic and information technologies.

\section{Materials and methods}

\section{Materials}

Object of the study is fuzzy automated energy management system of food manufacturing processes, designed to provide energy saving without losing performance.

In this study it is used:

- Electric power supply technologies of food manufacturing;

- Control methods of electric power supply of manufacturing processes;

- Mathematical models of control methods and algorithms;

- Simulation models created in matlab simulink computer software.

\section{Methods}

Plan of studies. The studies were conducted in the following order:

- Choosing control criteria of FMP power control system;

- Determining of control tasks of power supply and distribution of FMP;

- Designing a method for determining the node voltages of

- FMP power system for providing energy-efficient operation modes;

- Developing algorithms for fuzzy voltage regulation on the $0.4 \mathrm{kv}$ buses of the secondary substation transformers and on the $6-10 \mathrm{kv}$ buses of the primary substation transformer;

- Performing computer simulation of the algorithm and comparing with classical voltage regulation methods.

Control of power supply system of food manufacturing should ensure the achievement of the following objectives:

- Uninterrupted power supply of consumers while complying with industry specific and general energy standards of power quality;

- Standard quality of electrical power in substation supply voltage buses and district power distribution networks;

- Minimum possible level of losses in power systems;

- Permissible level of ecological safety in the conditions of electromagnetic field influence produced by electric networks and transmission lines.

Methods of system analysis. System description of FMP power system is performed with the use of tuple definitions [10], which is the simplest, most abstract tool; it enables the inclusion of different type objects and establishing connections of different nature and content. In this method the description of a system can be written in following form: 
where $\{M\}$ is a set of elements; $\{\varpi\}$ is a set of element links; $\Omega$ are the functions of described system.

Model of electrical network. It is used the combined topology of electrical network for modelling FMP power supply system on secondary substation level [15] as shown in Figure 1 , where $S_{\mathrm{NTi}}$ - nominal power of $i^{\text {th }}$ secondary substation transformer, $S_{i}$ - power of $i^{\text {th }}$ node load, $i=1,2,3, k ; l_{1}, l_{2}, l_{3}-$ the lengths of $1^{\text {st }}, 2^{\text {nd }}$ and $3^{\text {rd }}$ feeders of the linear segment of the network; $l_{k}$ - the feeder length of radial segment of the network.

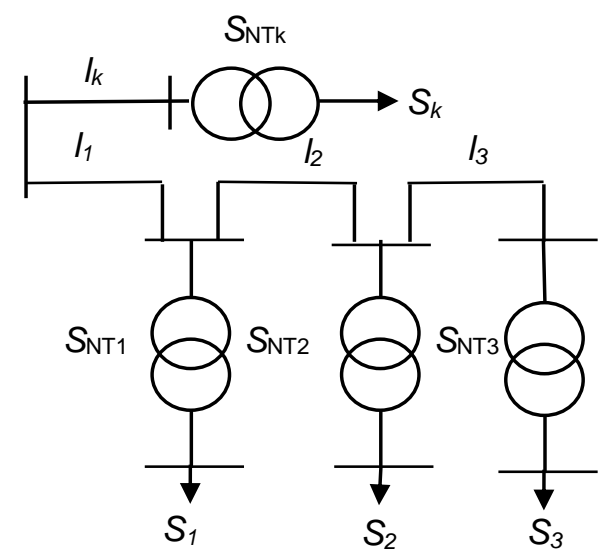

Figure 1. Combined topology network with connected SS transformers

Mathematical modelling. For mathematical modeling of control processes it is used state-space non-linear representation of control system [2].

$$
\frac{d X}{d t}=F(X, Z, U, K, t)
$$

where $\mathrm{X}$ is a $n$-dimensional state vector; $\mathrm{F}$ is $n$-dimensional nonlinear vector function; $Z$ is $m$-dimensional vector of perturbations; $U$ is $l$-dimensional vector of control actions; $K$ is $q$ dimensional vector that determines the structural parameters of control.

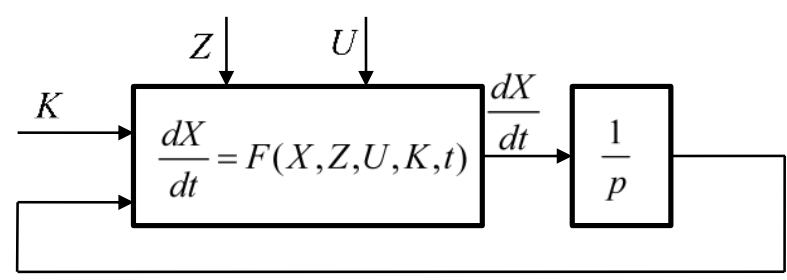

Figure 2. Structural diagram of control system

Methods of fuzzy control. For synthesis of fuzzy regulators it is used Mamdani and Sugeno fuzzy systems [14]. 
Methods of simulation analysis. For justifying algorithms of studied control system the simulation is used, which consist in modeling in the MATLAB Simulink environment of the operation modes of FMP power system controlled by the studied automated control system.

\section{Results and discussion}

\section{Control tasks and choosing control criteria}

Under operating conditions, the main optimal control criterion for the power supply system is just the minimum of variable component, which takes into account the costs of production, transformation and distribution of electrical power. In mathematical form, this criterion can be represented in the form of cost functional minimization [6]:

$$
I(t)=\int_{0}^{T}[\vec{Y}(t), \vec{X}(t), \vec{X}] d t \rightarrow \min
$$

where $\vec{X}$ is the vector of unchangeable output data, $\vec{X}(t)$ is the vector of output data, $\vec{Y}(t)$ is the vector of control parameters.

If it is considered the circuit of the grid unchanged, then in the vector $\vec{X}$ it is necessary to include data of the power system equipment, which determine the parameters of the equivalent circuit; performance characteristics of active and reactive power sources; utility power supply voltages. Vector $\vec{X}(t)$ includes data on the electrical loads of the enterprise, which change over time as the food manufacturing process continues. The control vector $\vec{Y}(t)$ contains the parameters that provide operation mode optimization by loading of active and reactive power sources, power flow at utility power supply connection node, changes of transformers turns ratios. The instantaneous value optimization problem is replaced with the control parameter optimization on a given time interval, which is equal to the averaging interval of the electric load graphs $\Delta t$. Then the multicriteria functional will look like this:

$$
I(t)=\sum_{i=1}^{T} g\left(\vec{Y}_{t}, \vec{X}_{t}, \vec{X}\right), \quad t=\overline{1, T}
$$

Since the loads of the individual nodes of the power supply system are probabilistic, therefore, the vector $\vec{X}$ is a vector of random variables. To move to the deterministic formulation of the problem, the vector $\vec{X}$ is replaced with the vector of expected values $M(\vec{X})$. Now the optimization problem is reduced to the solving $n$ deterministic problems of minimizing the cost functional, where $n$ is the number of load graph intervals.

The efficiency of the power supply system is estimated by the volume of electricity consumption and electricity losses in the power system.

The economic criterion of optimality is the minimum cost of electricity from the utility power system, generation of reactive power, loss of active and reactive power in electrical networks. In the deterministic formulation, the optimization problem can be formulated as follows: find the minimum of the functional of losses $L$

$$
\min \sum_{i=1}^{n} L\left(P_{i}, Q_{i}, K_{i}\right)
$$


Objective function $J$ of power supply control has the form

$$
J=\frac{M}{T} \int_{0}^{T}\left\{\sum_{j=1}^{n m} \Delta P_{j L N}+K_{Q} \sum_{j=1}^{m} \Delta Q_{j L N}+\sum_{i=1}^{n} \Delta P_{i U S}+K_{Q} \sum_{i=1}^{n} \Delta Q_{i U S}\right\} d t \rightarrow \min _{X(t) \in \Omega}
$$

where $M$ is expected value of active and reactive power losses; $T$ is the estimated time interval; $\Delta P_{i U S}, \Delta Q_{i U S}$ are the active and reactive power losses at the SS level; $\Delta P_{j L N}, \Delta Q_{j L N}$ are the active and reactive power losses at the $i^{\text {th }}$ load node.

\section{System analysis and mathematical modelling}

Achieving goals described above is impossible without creation of effective mathematical model. The controlled object during the operating control is the power supply and distribution system of food manufacturing processes (PSDS FMP), which has a hierarchical structure and is operated using open tree-like schemes.

Power system of food industry enterprise is a complex nonlinear dynamic object, for which the following model can be formally described in the form (2), where $\mathrm{X}$ is a $n$ dimensional vector of parameters, that characterize the operation mode; $\mathrm{F}$ is $n$-dimensional nonlinear vector function; $Z$ is $m$-dimensional vector of perturbations (time-variable active and reactive loads of consumers); $U$ is $l$-dimensional vector of control actions, which is formed on the basis of a deterministic or accidental change of the technological process of the enterprise, as well as changes in the parameters of the operation mode and restrictions of the power system; $K$ is $q$-dimensional vector that determines the structural parameters of PSDS FMP.

Considering the large dimension, complexity and insufficient information base of PSDS FMP, controlling procedures use its simulation models. The concept of instant circuits is applied and the dynamic model (2) is reduced to a set of static circuits. To perform the simulation procedure, the study interval $T_{M}$ is divided into intervals $\Delta t$, within which the parameters $X, U, K, Z$ are accepted unchanged.

At each simulation interval $\Delta t$, the following nonlinear system of equations is solved, which describes the steady state mode of the corresponding instant circuit:

$$
F\left[X_{k}, S_{k}, C_{k}, V_{k}\right]=0
$$

where $X_{k}, S_{k}, C_{k}, V_{k}$ are parameter values of vectors $X, S, C, V$ for $k^{\text {th }}$ instant circuit.

The system description of PSDS FMP is performed with the use of tuple definitions (1) and can be written in this form [10]:

$$
\Sigma_{P S D S}:\{\{M\},\{\varpi\}, \Omega\}
$$

where $\{M\}$ is a set of PSDS FMP elements; $\{\varpi\}$ is a set of element links; $\Omega$ are the functions of PSDS FMP.

For automated PSDS FMP of modern type the element of type $\{M\}$ can be represented this way

$$
\{M\}:\left\{M^{(t)}\right\},\left\{M^{(I)}\right\},\left\{M^{(I I)}\right\}
$$

where $\left\{M^{(t)}\right\}$ are the technical means; $\left\{M^{(I)}\right\}$ are information technology means, including human-machine interface, software and databases; $\left\{M^{(I I)}\right\}$ are the other elements. 
The links between PSDS FMP elements can be shown the following way

$$
\{\varpi\}:\left\{\varpi^{(M X)}\right\},\left\{\varpi^{(E)}\right\},\left\{\varpi^{(M E)}\right\},\left\{\varpi^{(I)}\right\}
$$

where $\left\{\varpi^{(M X)}\right\}$ are the mechanical links; $\left\{\varpi^{(E)}\right\}$ are electrical links; $\left\{\varpi^{(M E)}\right\}$ are electromechanical links, created by electromagnetic field; $\left\{\varpi^{(I)}\right\}$ are informational links.

It was noted above that the PSDS FMP actively interacts with the electric power grid (EPG), which should be taken into account when creating a mathematical model. Then it can be written in the form

$$
\{M\}: \bigcup_{r=I}^{R}\left\{M^{(r)}\right\} ;\{\varpi\}: \bigcup_{r=I}^{R}\left\{\varpi^{(r)}\right\}
$$

where $R=3 ;\left\{M^{(I)}\right\}$ corresponds to the EPG elements that must be taken into account in a mathematical model of the entire system; $\left\{M^{(2)}\right\}$ - the set of elements of PSDS FMP; $\left\{M^{(3)}\right\}$ are elements of district electric grids (DEG), the consideration of which is necessary for an adequate description of the processes in the combined system of EPG, PSDS FMP and DEG.

A symbolic description of the PSDS FMP processes can be represented as follows:

$$
S_{n}\left[X\left(t_{0}\right)\right]=X(t), X \in \mathrm{R}^{n}, t \in T
$$

The process $S_{n_{0}}$ is a rule of transition from the state with the parameter value (time) $t_{0}$ to the state with the value $t>t_{0}$ through all its intermediate continuous or discrete values. The process $S_{n_{0}}$ is associated with a mapping of sets $T \times X \rightarrow X_{t}$.

To study the processes $S_{n_{0}}$ it is used a combined method: determination of static load characteristics in the interactive mode and calculation of the parameters of the operation mode.

A formal description of the PSDS FMP model can be presented as a tuple

$$
\sum_{P S D S}^{(M)}:\{X, A, B, t, \aleph\}, X \in \mathfrak{R}^{n}, A \in \mathfrak{R}^{m}, B \in \mathfrak{R}^{w}, t \in T
$$

where $X$ is a time-variable parameter vector; $B$ is a input parameter vector; $A$ is a timeinvariant parameter vector, which includes structural parameters of substations, distribution system and transmission lines; $\aleph$ is a rule of determining parameters of $X$. The vector $\mathrm{B}$ includes load powers $V=V(t)$ and structural parameters of PSDS FMP model that varies depending of power consumer configuration changes.

For modeling of operation modes of the open PSDS FMP electrical network, the voltages at network nodes are determined by the equations [17]:

$$
U_{i}=U_{N}-\frac{1}{U_{N}} \sum_{i=1}^{n}\left(P_{i} R_{i}+Q_{i} X_{i}\right)
$$

Without taking into account the power losses in the enterprise distribution network, the voltage losses are calculated in separate sections of the line by fixing loadings of SS $\left(S_{1}, S_{2}, \ldots, S_{n}\right)$ or the powers $\left(S_{1}, S_{2}, \ldots, S_{n}\right)$ that flow over the sections. The total voltage loss in the line from the power source to any node $i$ is determined by the sum of the voltage loss in each section and calculated by the formula:

$$
\Delta U_{0 i}=\frac{1}{U_{N}} \sum_{i=1}^{n}\left(p_{i} r_{i}+q_{i} x_{i}\right)=\sqrt{3}\left(\sum_{i=1}^{n} i_{a i} r_{i}+\sum_{i=1}^{n} i_{p i} x_{i}\right)
$$


To model the modes of PSDS FMP closed electrical networks it is used the node potential method [17]. The system is described using the linear system of equations:

$$
\underline{\mathbf{Y}} \cdot \underline{\mathbf{U}}=\underline{\mathbf{I}}
$$

where $\underline{\mathbf{U}}$ is a vector of node potentials; $\underline{\mathbf{I}}$ is a vector of node currents; $\underline{\mathbf{Y}}$ is a matrix of node admittances, which consists of $\underline{\mathbf{Y}}_{i i}$ - the sum of admittances that connected to node $i$ and $\underline{\mathbf{Y}}_{i j}=\underline{\mathbf{Y}}_{j i}, i \neq j-$ negative values of admittances between nodes $i$ and $j$.

Therefore, $\underline{\mathbf{Y}}$ is a symmetric matrix and the sum of all columns and rows is zero.

Unknown node voltages can be obtained using an inverted matrix:

$$
\underline{\mathbf{U}}=\underline{\mathbf{Y}}^{-1} \cdot \underline{\mathbf{I}}
$$

In the simplest case, the voltage at the power supply node is specified, and the power of the consumers must be set as a voltage dependent according to (15). Using the nominal voltage, the power consumer admittance matrix, which is part of the node admittance matrix, is determined once:

$$
\underline{\mathbf{Y}}_{k}=\frac{\underline{S}_{k}^{*}}{U_{n}^{2}}
$$

This process is called linear power flow. However, if the nodal powers of the consumers, calculated by nodal voltages and the consumers' admittance matrices, do not match the set values, then the calculated voltages are taken to be equal to the nominal voltage. The resulting variations are acceptable if the deviation of the calculated voltage from the nominal voltage is low or the consumer admittance is considered constant.

At the given constant power of the nodes, the relation between the full power and the voltage is calculated by (18).

$$
\underline{S}_{k}=U_{k}^{2} \cdot \underline{\mathbf{Y}}_{k}^{*}
$$

It is shown on the basis of (18) that the problem of load current is reduced to a nonlinear quadratic system of equations for node voltage. The above system of equations is solved by some iterative method such as Newton-Raphson method [11].

\section{Justification of FMP power supply control algorithms}

In order to provide energy efficient modes of power transmission in PSDS FMP, energy efficient voltage levels are maintained at the nodes of the system [2] by regulating reactive power sources, as well as the voltage of secondary substation (SS) and primary substation (PS) transformers.

The values of effective voltage levels at the PS level are calculated on the basis of realtime static characteristics of the complex load (SCL) [11], and voltages at the PS transformers level - on the basis of the calculation of $6-10 \mathrm{kV}$ distribution electrical network modes.

The SS voltage regulator reference values are calculated on the basis of active $P_{L V}$ and reactive power $Q_{L V}$ values, which are measured on SS low-voltage side, parameters of SS $10 \mathrm{kV}$ power supply system (radial, linear or combined connection schemes), cable line lengths $L_{k}$, transformer technical data, static load characteristics on the SS low-voltage (LV) side $\Delta P_{S S^{*}}\left(U_{S S^{*}}\right)=A_{1} \cdot \Delta U_{S S^{*}}$, identified for the main operation modes in real-time.

The reference values are calculated in the following order. The following factors are determined: SS transformer load $\alpha=\sqrt{P_{L V}^{2}+Q_{L V}^{2}} / S_{L V}$; reactive power $\operatorname{tg} \varphi=Q_{L V} / P_{L V}$; 
active power $\cos \varphi=P_{L V} / \sqrt{P_{L V}^{2}+Q_{L V}^{2}}$; active load $\alpha_{A}=\alpha \cdot \cos \varphi$, and the degree of reactive power compensation $\beta_{Q}=Q_{B K N} / Q_{P N}$. Using equilibrium coefficient of the secondary network for active power $A_{1 i}$, obtained by SCL of the $i^{\text {th }} \mathrm{SS}$ transformer, it is calculated the value of the equilibrium voltage on the bus $0.4 \mathrm{kV}$ of $i^{\text {th }} \mathrm{SS}$.

We take the equilibrium voltage on the LV SS buses as the reference value SS voltage regulator.

The equivalent circuit of combined topology network (Figure 1) is shown in Figure 3, where $R_{E C 1}, R_{E C 2}, R_{E C 3}$ are equivalent circuit resistances of $1^{\text {st }}, 2^{\text {nd }}$ and $3^{\text {rd }}$ branches of linear segment; $R_{E C k}$ is equivalent circuit resistance of radial segment branch; $R_{T S i}$ - equivalent resistance of $i^{\text {th }}$ transformer; $S_{i}$ - power of $i^{\text {th }}$ node load, $i=1,2,3, k ; l_{1}, l_{2}, l_{3}$ - the lengths of $1^{\text {st }}$, $2^{\text {nd }}$ and $3^{\text {rd }}$ feeders of the linear segment of the network; $l_{k}$ - the feeder length of radial segment of the network; $r_{01}, r_{02}, r_{03}, r_{0 \mathrm{k}}-$ per unit length resistance of feeders; $U_{N}-$ nominal voltage of network, and

$$
\begin{aligned}
& R_{E C 1}=\frac{\left(1+\frac{2\left(S_{2}+S_{3}\right)}{S_{1}}\right) r_{01} l_{1}}{3 U_{N}^{2}} ; R_{E C 2}=\frac{\left(1+\frac{2 S_{3}}{S_{2}}\right)\left(r_{01} l_{1}+r_{02} l_{2}\right)}{3 U_{N}^{2}} ; \\
& R_{E C 3}=\frac{\left(r_{01} l_{1}+r_{02} l_{2}+r_{03} l_{3}\right)}{3 U_{N}^{2}} ; R_{E C k}=\frac{r_{0 k} l_{k}}{3 U_{N}^{2}} ; R_{T S i}=\frac{\Delta P_{S C i}}{S_{N T i}^{2}} .
\end{aligned}
$$

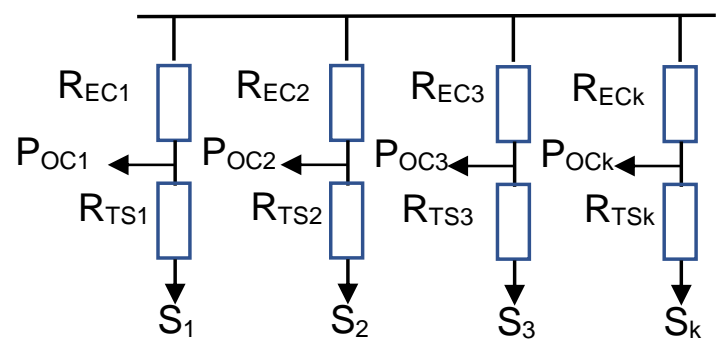

Figure 3. Equivalent radial circuit of combined topology network

Using the technical specifications of electrical equipment and the current values of active and reactive power of the generalized electric receiver, which are measured on the buses of LV SS, for all segments of the SS connection (Figure 1), it's obtained the following expressions for the equilibrium voltage:

$$
\Delta U_{S S i * 0}=\frac{\Delta P_{O C i}+S_{i}^{2}\left[R_{E C i}+\frac{\Delta P_{S C i}}{S_{N T i}^{2}}\right]}{A_{1 i} \cdot P_{N i}}=\frac{\Delta P_{O C i}+S_{i}^{2}\left[R_{E C i}+R_{T S i}\right]}{A_{1 i} \cdot P_{N i}}, i=1,2,3, k .
$$

where $A_{1 i}$ - coefficient of linearized static characteristic of $i^{\text {th }}$ node load; $P_{N i}$ - nominal active power of $i^{\text {th }}$ node load, $\Delta P_{O C i}-$ open circuit power losses; $\Delta P_{S C \mathrm{i}}-$ short circuit power losses. 
When adjusting SS voltage, the equilibrium voltage is the reference value of the SS voltage regulator and is calculated for the main operation modes of the power supply system using static load characteristics on the SS buses according to the voltage, which are determined in the interactive mode.

In order to maintain the energy efficient modes of FMP, the PSDS FPM provides for the use of fuzzy voltage regulators of the SS transformers and PS transformer.

\section{Justification of energy efficient 6-10 $\mathrm{kV}$ distribution network voltages}

The voltage regulation in the $6-10 \mathrm{kV}$ distribution network is carried out by adjusting the voltage of the PS transformer by means of on-load tap changer [11]. The main purpose of voltage regulation is to reduce power losses in the $6-10 \mathrm{kV}$ electrical network and to provide conditions for voltage regulation of the SS transformers when changing the voltage on the high voltage (HV) side of the SS, depending on the load and the voltage on the HV side of the PS transformer (maximum and minimum load of the grid). This implies maintaining voltage levels on the $6-10 \mathrm{kV}$ buses the electrically closest and most distant SS, which provide conditions for the effective operation of PSDS FPM at all SSs under load change. Energy efficient voltage levels in the 6-10 kV network are calculated on the basis of a real-time mathematical model for the characteristic modes of the power system based on the measured currents and the voltage of the PS transformer [3]. Determination of the farthest and the closest connections is made in real time using measured currents, voltages and power of individual connections based on fuzzy logic using the following parameters: load power $S$, line length $L$, voltage regulating effect $P(U)$, load distribution along the line $R(L)$, availability of reactive power compensation devices $C$. A block diagram of the fuzzy controller for selecting the most distant and the closest lines to the power center of is shown in Figure 4.

\section{Synthesis of fuzzy regulation of the voltage of the SS transformer}

When adjusting the voltage in the secondary electrical network should be provided:

- Compliance of voltage indicators with the requirements of the official standard;

- Compliance of the voltage level with the value permissible for the equipment of the electrical networks, taking into account permissible operational increases of the industrial frequency voltage on the electrical equipment (according to the data of manufacturers and circular saws);

- Minimum consumption and loss of electricity in the secondary electrical networks.

Voltage modes are selected depending on the type of secondary electrical network (radial, linear, combined), the nature of the consumers connected to the secondary network, their distance from the secondary substation.

An algorithm for fuzzy voltage regulation of the SS transformer with an electronic switch is built using the Mamdani algorithm [2]. The structure of the fuzzy regulator of the SS transformer is presented in Figure 5. For the implementation of control functions, a database was created for a fuzzy SS voltage regulator. 


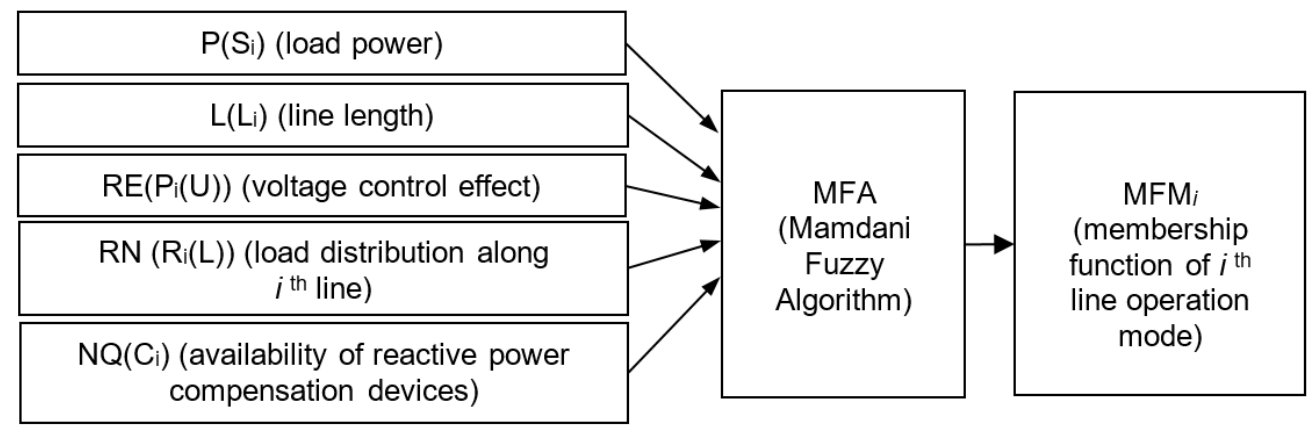

$a$ - algorithm of fuzzy determining of $i^{\text {th }}$ line operation mode

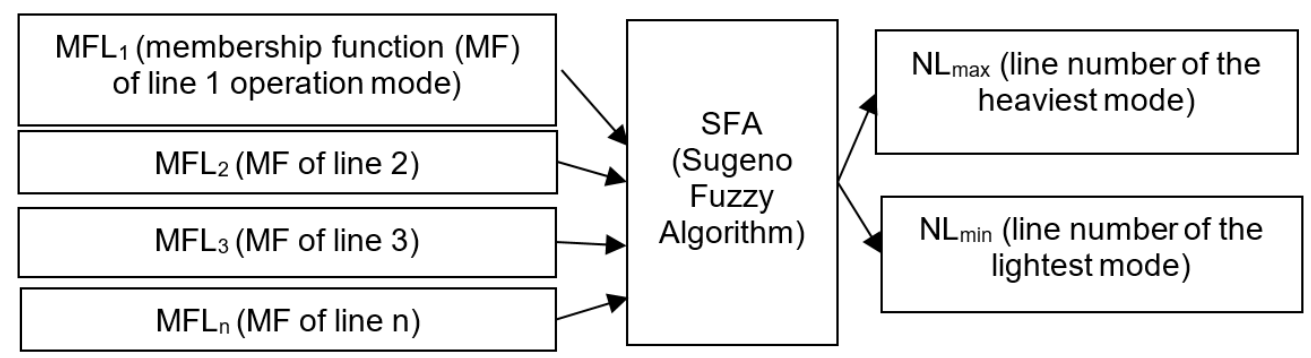

\section{$b$ - algorithm of fuzzy determination of the closest and the farthest line connection}

Figure 4. Block diagram of fuzzy connection selection with the heaviest and lightest operation modes of the closest and the most distant connections

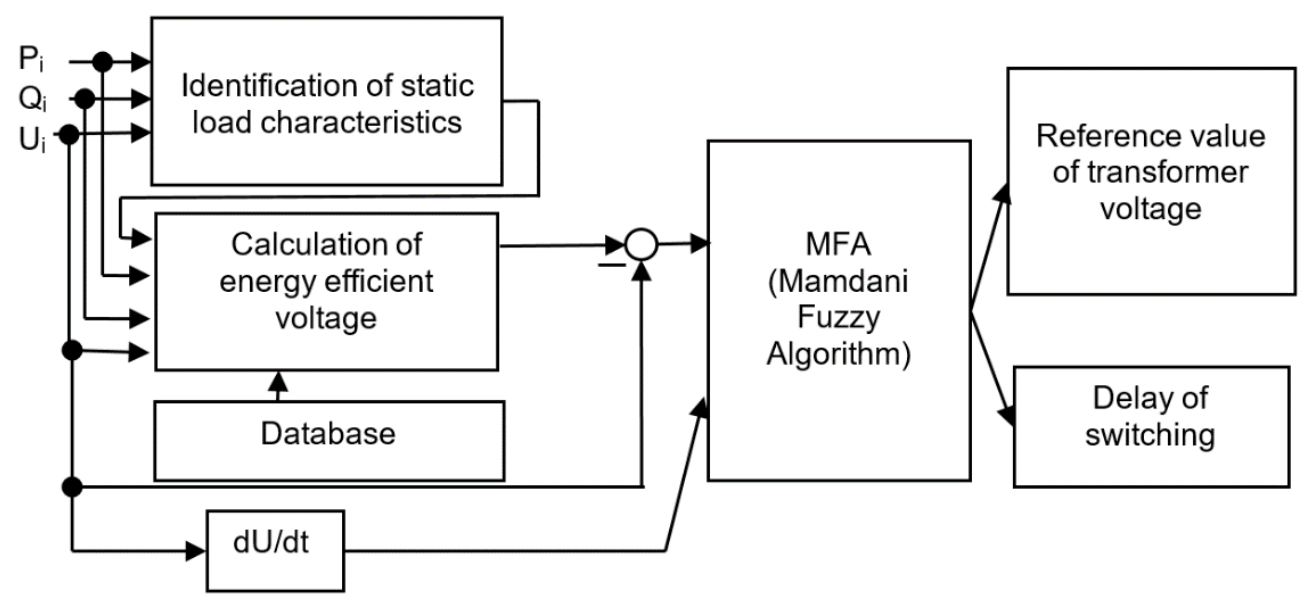

Figure 5. Block diagram of a fuzzy voltage regulator of the SS transformer 


\section{Synthesis of fuzzy voltage regulation at the PS transformer level}

The structure of the fuzzy regulator of the on load tap changing PS transformer is presented in Figure 6.

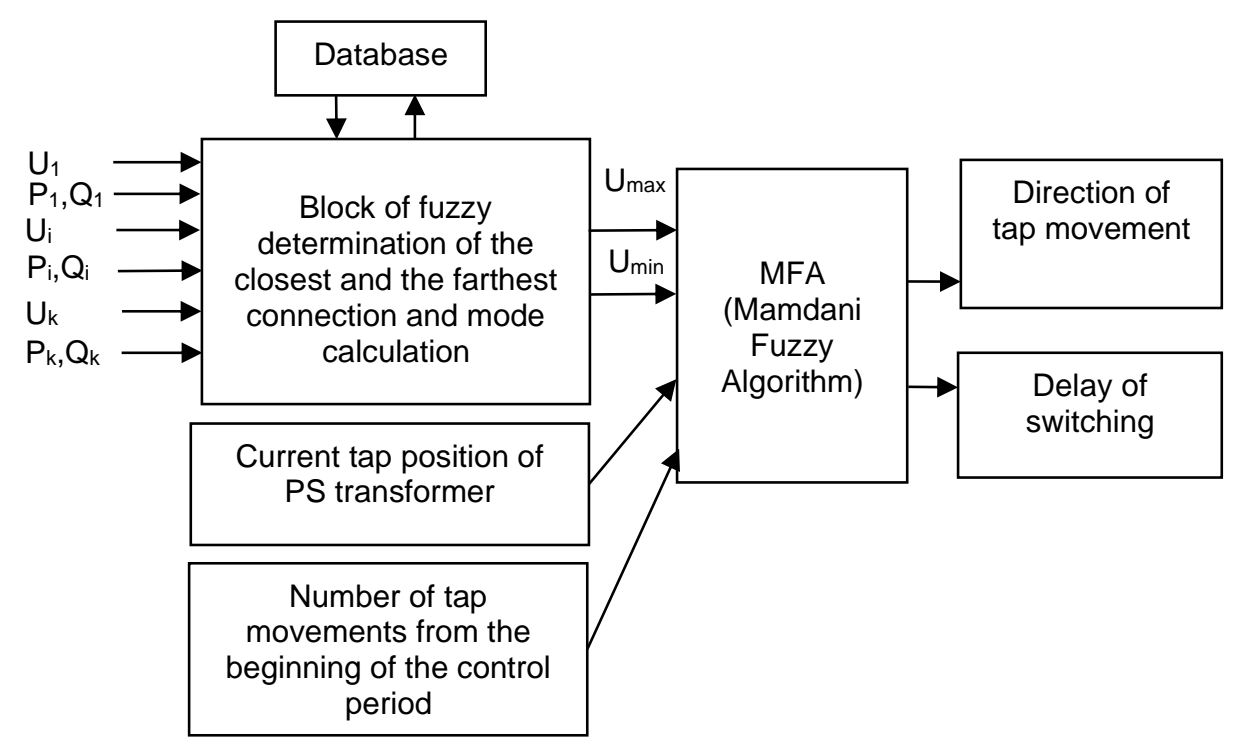

Figure 6. Block diagram of fuzzy voltage regulator of PS transformer

The values of the fuzzy output variable "direction" were defined as follows: at a voltage below nominal ("very low", "low"), the tap changer direction should correspond to the values "down", and at high voltage ("high", "very high") the tap changer direction is up. In cases where the voltage is approximately equal to the rated ("normal"), the tap changer does not fire ("stop").

\section{Simulation results of PS fuzzy controller operation}

To study proposed algorithms and mathematical model in Simulink environment on the PS level, it was created a computer model of a $110 / 10 \mathrm{kV}$ substation, to which a non-linear dynamic load is connected. The block diagram of the simulated system is presented in Figure 7 , where Source $110 \mathrm{kV}$ is a block describing the $110 \mathrm{kV}$ power system; Transformer - block describing model of three-phase power transformer 110/10kV; Line - blocks that define the parameters of the line; V-I measurement - blocks of measurement of current values of current and voltage; Dynamic load - blocks that simulate three-phase dynamic loading; Power demand - units that have the task of changing the power consumption for the dynamic load units; Fuzzy-logic controller - fuzzy controller block; On-load regulator - blocks of voltage regulation of the power transformer on load. 


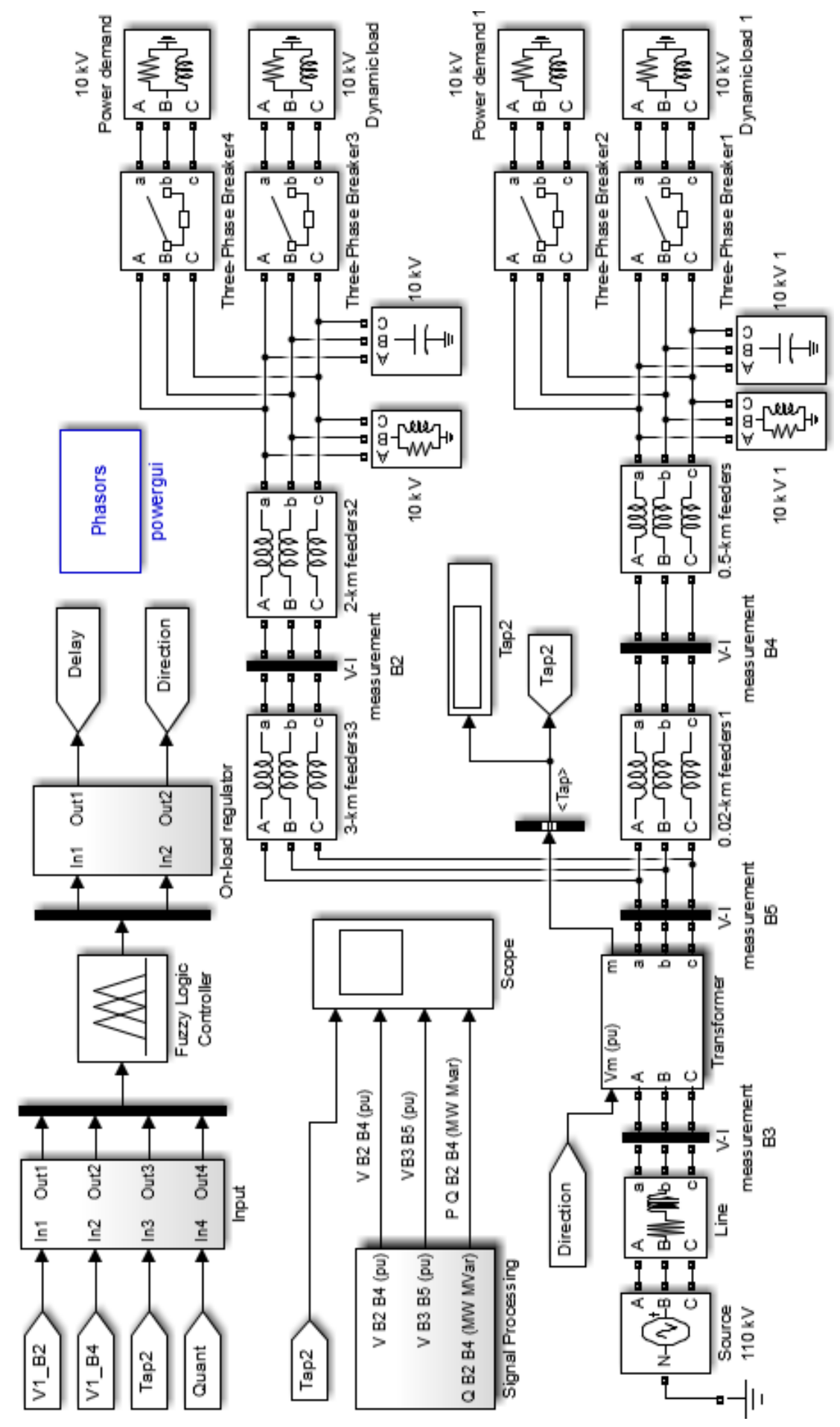

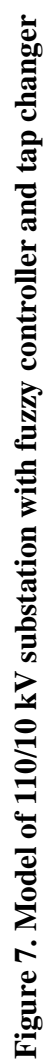


Using the model it is obtained graphs of voltage changes depending on the load in time. Figure 8 shows graphs of voltage changes at $110 \mathrm{kV}\left(\mathrm{V}_{\mathrm{B} 3}\right)$ and $10 \mathrm{kV}$ substations $\left(\mathrm{V}_{\mathrm{B} 5}\right)$, voltage and load on the remote $\left(\mathrm{V}_{\mathrm{B} 2}\right)$ and near-consumer $\left(\mathrm{V}_{\mathrm{B} 4}\right)$ bus loads. The analysis of the obtained voltage graphs showed that the developed algorithm of voltage regulation based on fuzzy systems ensures the maintenance of the given voltage levels at the nodal points of the distribution network when changing the voltage of the power source and when changing the load of consumers according to different schedules.
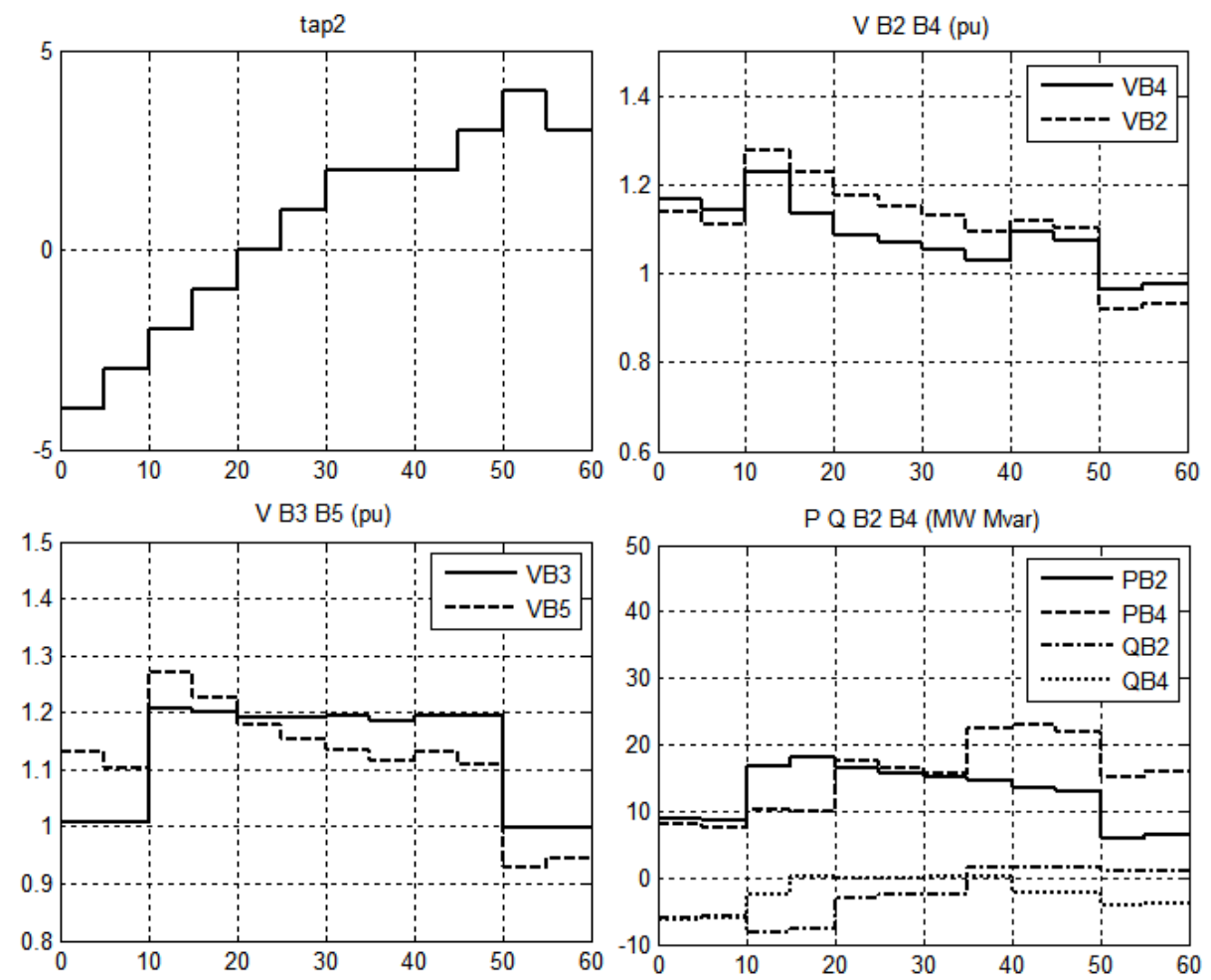

Figure 8. Graphs of voltage and load changes in the distribution network.

The implementation of the proposed algorithm for voltage regulation based on fuzzy sets allows to maintain rational levels of voltage in the distribution network, which are obtained on the basis of analysis and optimization of the modes of the electrical distribution network, which will ensure a rational level of electricity losses.

\section{Simulation results of SS fuzzy controller operation}

As a research object in the Simulink environment at the SS level, a computer model of a $10 / 0.4 \mathrm{kV}$ substation was created, to which a nonlinear dynamic load is connected to the tires. The block diagram of the simulated system is presented in Figure 9, where Source 10 $\mathrm{kV}$ is a unit describing the $10 \mathrm{kV}$ power system; Transformer - block describing the model of three-phase power transformer $10 / 0.4 \mathrm{kV}$; Line - blocks that define the parameters of the airline; V-I measurement - block of measurement of current values of current and voltage. 


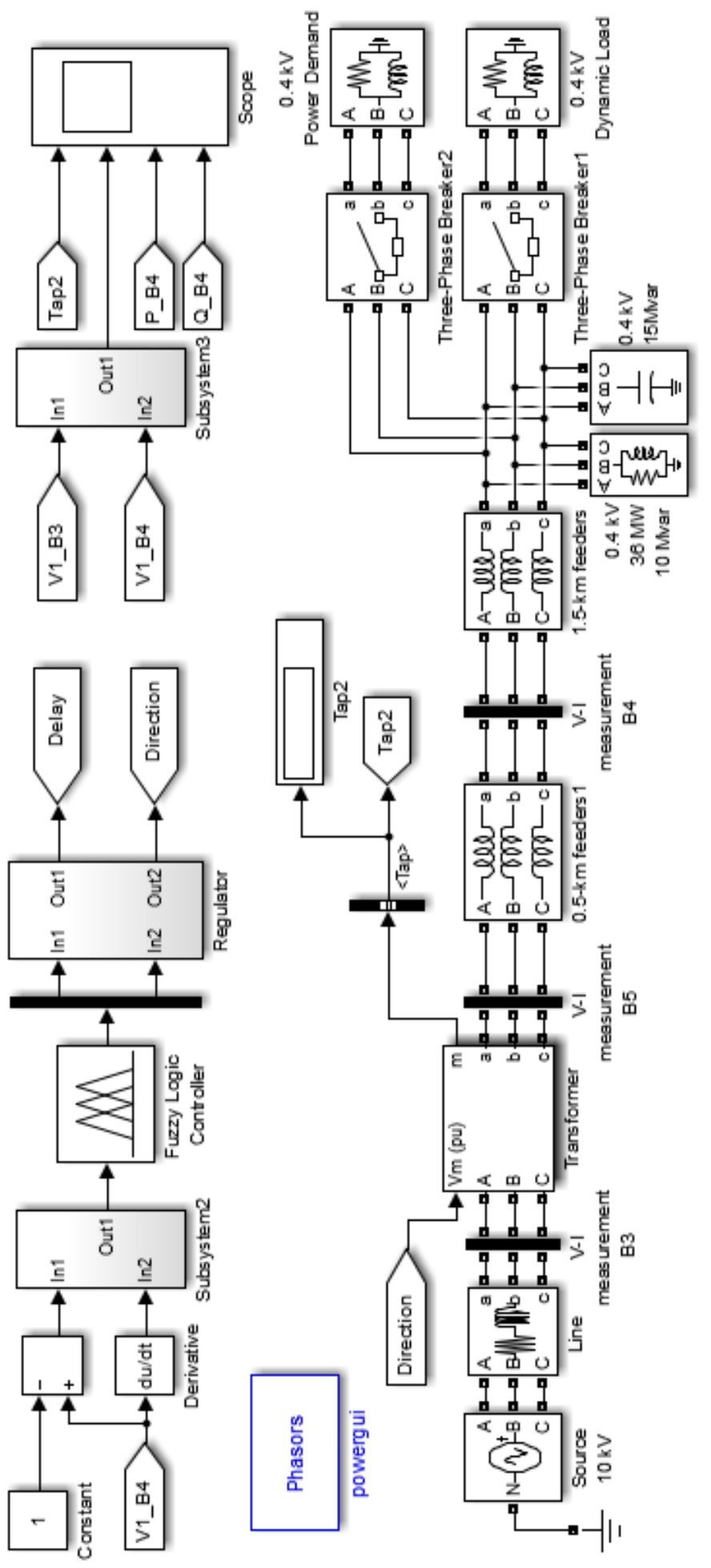

है 
The results of computer simulation of the SS fuzzy controller operation under different modes of the secondary network: loading and dropping load; switching capacitors on and off; change of supply voltage are presented in Figure 10.
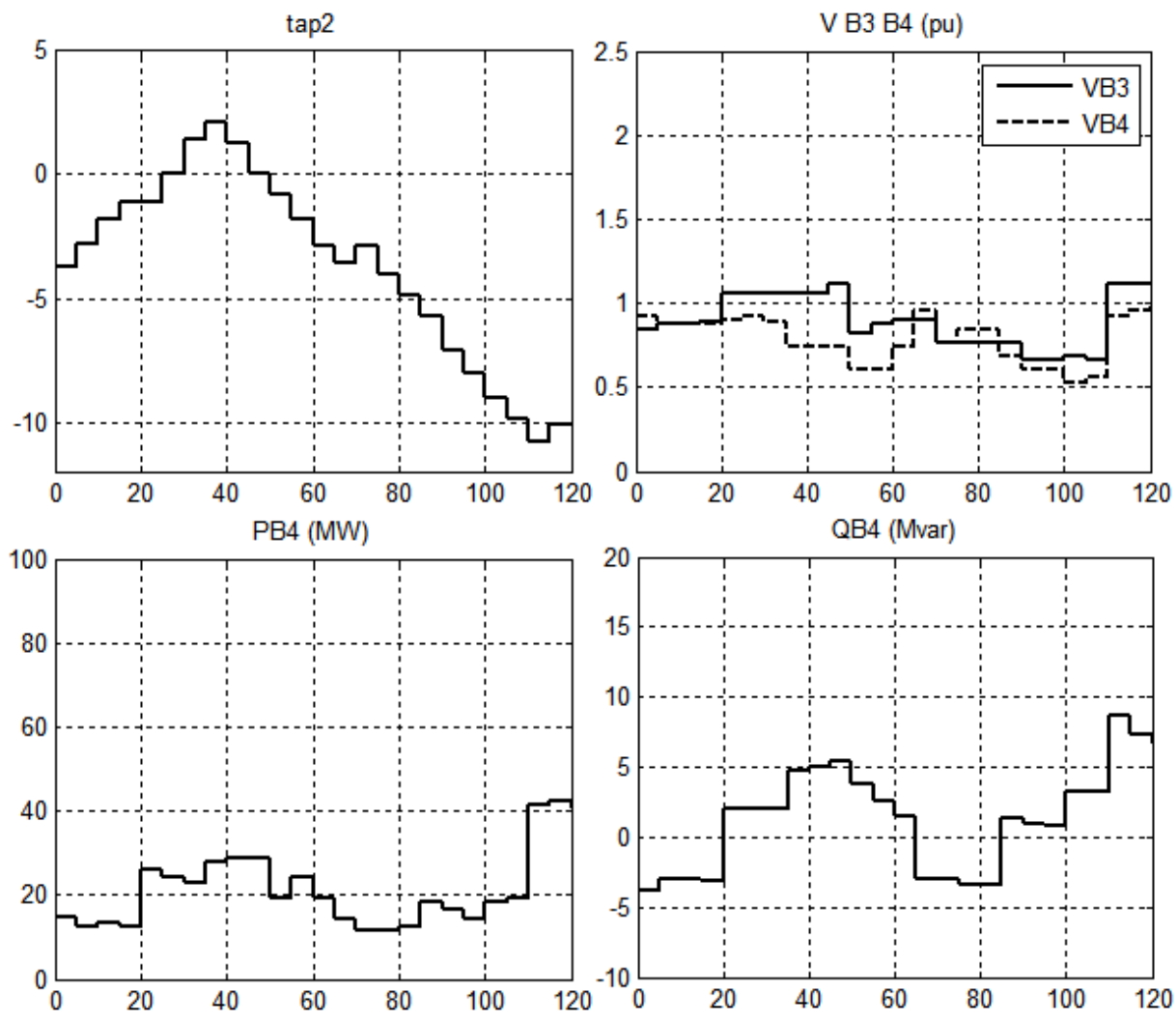

Figure 10. Graphs of voltage and load changes in the secondary network

Figure 11 shows the daily graphs of power loads of food manufacturing process $\mathrm{W}(\mathrm{pu})$ and voltages V (pu). Graph of voltages which demonstrates the results of two different ways of controlling the voltage regime: classical [11] and fuzzy, as well as process without control.

The results of the computer simulation made it possible to estimate the losses of electrical energy in the electrotechnical complex in relative units when comparing the results of the operation of the classical regulator of the load regulation device and the fuzzy controller. As it can be seen in Figure 12, the use of fuzzy control of transformer with an electronic switch allows to reduce electricity losses by $7 \%$ compared to the classical voltage regulation algorithm. 

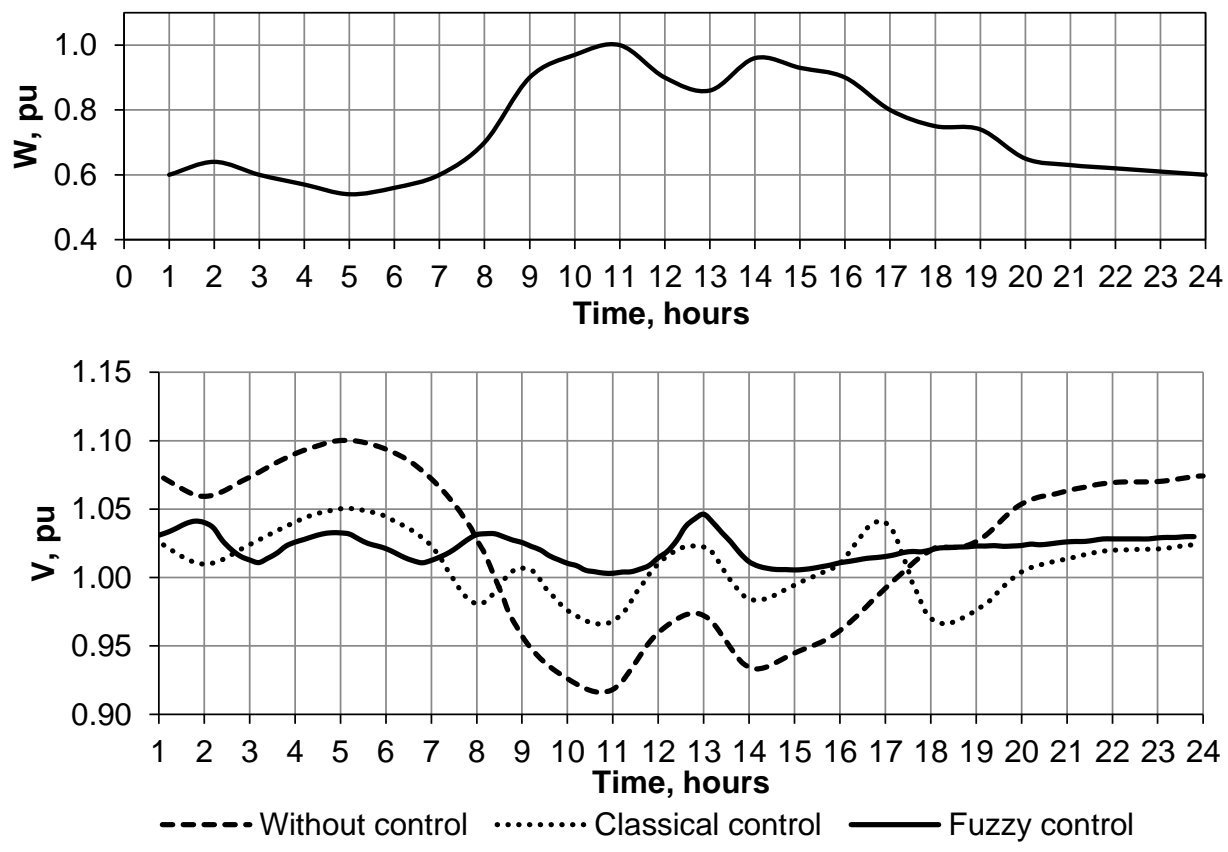

Figure 11. Changing the voltage deviation on the SS buses during the day

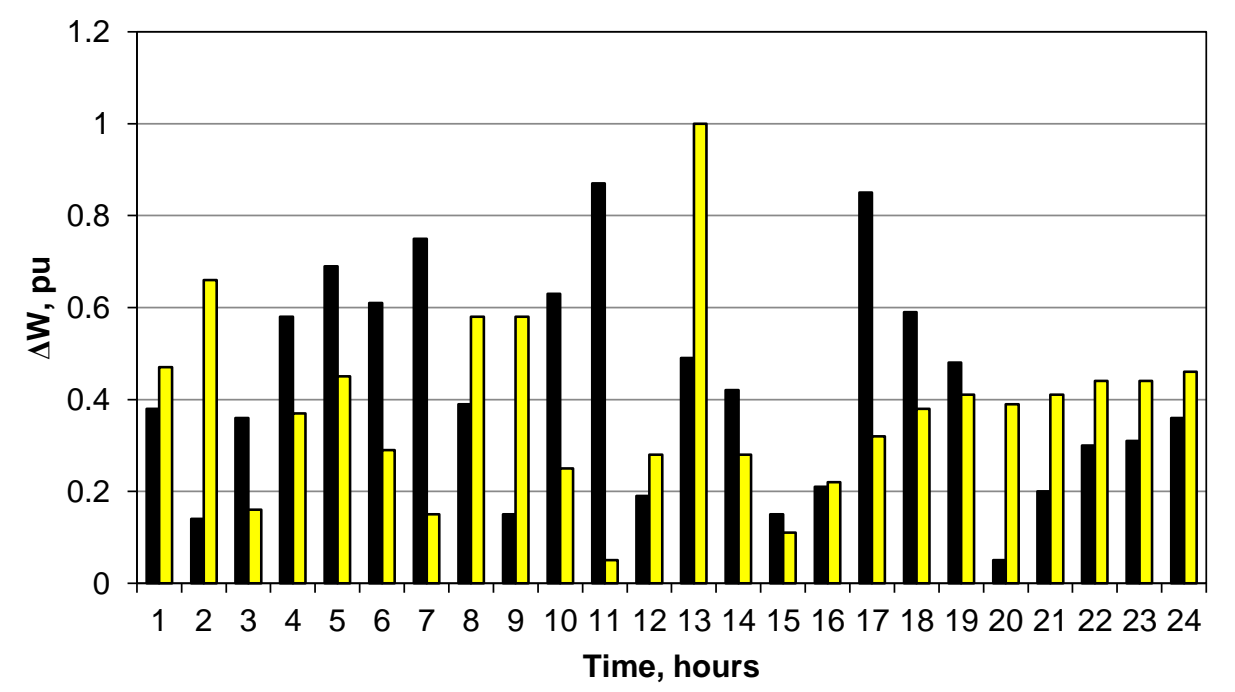

-Energy losses when using classical control algorithm 口Energy losses when using fuzzy control

Figure 12. Changing the relative losses of electricity during the day with different methods of voltage regulation on SS buses 


\section{Conclusion}

Based on methods of system analysis such as tuple definition and decomposition methods it was identified links between heterogeneous elements of the energy supply system of food manufacturing processes and built the mathematical model. This model made it possible to estimate energy efficient modes of the power supply system. Fuzzy controllers at SS and PS level were developed to maintain these energy efficient modes during food manufacturing processes.

Using the results of the computer simulation of algorithms of SS and PS fuzzy controllers in MATLAB Simulink environment the losses of electrical energy were estimated comparing to the results of the classical regulator operation in main operation modes of food manufacturing. The results showed that the use of our method allows reducing electricity losses up to $7 \%$ compared to the classical voltage regulation algorithm.

\section{References}

1. Baliuta S.M., Izvolenskyi I.Ye., Shesterenko V.Ye. (2012), Optimal mode of operation of reactive power of the enterprise, Scientific works of NUFT, 45, pp. 61-66.

2. Baliuta S.M., Yovbak V.D., Kopylova L.O., Korolyov Ye.O. (2017), Voltage control system with fuzzy controllers in the industrial power supply system, Scientific works of NUFT, 23(1), pp. 173181

3. Baliuta S.M., Yovbak V.D., Kopylova L.O., Lytlyn I.Yu. (2017), Mathematical model of power consumers for voltage control of secondarysynthesized transformer, Scientific works of NUFT, 23(3), pp. 126-140.

4. Belousenko I.V., Golovatov S.A., Goryunov I.V., Ershov M.S., Trifonov A.A. (2012), Functional tasks of the automated control system for electric power supply of Gazprom power supply facilities. Operational calculation of power supply modes, Scientific works of the Oil and Gas University named after I.M. Gubkin, 3(268), pp. 118-124.

5. Vasyl Kishenko, Borys Goncharenko, Oleksii Lobok, Viacheslav Ivashchuk, Maryna Sych (2017), Scenarios of intellectual fuzzy automated control of bread production, Ukrainian Journal of Food Science, 5(2), pp. 103-114.

6. Burghes D. and Graham A. (2004) Control and optimal control theories with applications, Antony Rowe Ltd, Eastbourne.

7. Cheremisin M.M., Kholod A.V. (2012), Integrated automation of energy objects based on modern SCADA systems, Bulletin of Vinnitsa Polytechnic Institute, 3, pp. 128-131.

8. Choi J.H., Kim J.C. (2001), Advanced voltage regulation method of power distribution systems interconnected with dispersed storage and generation systems (revised), IEEE Transactions on Power Delivery, 16(2), pp. 329-334.

9. Chukreev Yu.Ya., Khokhlov M.V., Lla E.L. (2000), Operational management of the regional energy system using neural networks, Electricity, 4, pp. 2-10.

10. Gibson J.E., Scherer W.T., Gibson W.F., Smith M.C. (2017), How to do system analisys, y: John Wiley \& Sons, New Jerse

11. Hrabko V.V. (2005), Models and means of voltage regulation using transformers with tap changers, UNIVERSUM-Vinnytsia, Vinnytsia.

12. Jagtap S., Rahimifard S., Duong L. (2019), Real-time data collection to improve energy efficiency: A case study of food manufacturer. Journal of food processing and preservation, Special Issue 2019, pp. 1-7, DOI: 10.1111/jfpp.14338.

13. Ladha-Sabur A. et al. (2019), Mapping energy consumption in food manufacturing. Trends in Food Science \& Technology, 86, pp. 270-280.

14. Lilly J.H. (2010), Fuzzy control and Identification, John Wiley \& Sons, New Jersey. 
15. Liu Y., Zhang P., Qiu X. (2000), Optimal reactive power and voltage control for radial distribution systems, IEEE Power Engineering Society Summer Meeting, 1, pp. 85-90.

16. Prystupchuk A., Movchan S., Panov A. (2012), MICROSCADA PRO automated control systems using remote terminals. RTU management as a reliable solution for all levels of automation, Electric networks and systems, 3, pp. 95-104.

17. Singh A.K. and Pal B.C. (2019), Dynamic estimation and control of power systems, Academic Press, London.

18. Steimle W., Thoma M., Wille-Haussmann B. (2006), Intelligent Energy Management in Low Voltage Grids with Distributed Resources, IEEE Transactions on Power Systems, pp. 125-135.

19. Tarasov D.M., Khachaturian V.A. (2001), Management of voltage regimes in the distribution networks of mining enterprises, Science at SPb technical university. Notes of the Mining Institute, 151, pp. 123-127.

20. Veres O.M., Polotskyi A.B. (2011), Conceptual model of the information system of decisionmaking on power supply control, Bulletin of Lviv Polytechnic National University: Information systems and networks, 715, pp. 50-59.

21. Wasiak I., Wasiak M., Thoma C., Foote R., et al. (2006), A Power Quality Management Algorithm for Low-Voltage Grids with Distributed Resources, IEEE Transactions on Power Delivery, 23(2), pp. 1055-1062.

22. Yevtukh P., Orobchuk B., Rafaliuk O. (2008), Automated system of dispatching control of power supply of district grids, Bulletin of Lviv Polytechnic National University, 615, pp. 190-194.

23. Zhmak V.I., Manusov V.I. (2002), Justification of the principle of fuzzy voltage regulation using on-load tap-changer transformer, Power industry, pp. 32-42.

24. Kopylova L., Baliuta S, Mashchenko O. (2017), Methods and algorithms of food industry enterprises electrical energy consumption control, Ukrainian Journal of Food Science, 5(2), pp. 267-283.

25. Bulayev Yu.V., Tabakov V.A., Eskin V.V. (2001), Integrated automation of energy supply of enterprise, Industrial energy, 2, pp. 11-15. 